merits; but I wish to refer those interested in the subject to another method of applying the oil, as it is one whiah, though I have not used it, theoretically commends itself to my mind; and which I have not seen alluded to by Dr. Alder Smith, or by any subsequent writers. At the same time, it will, I doubt not, interest the readers of the JoURNAL to know the name of the originator of this treatment and the date of its publication. This information is to be found in an article published in 1876, in Le Bulletin Général de Thérapentique (p. 97), where the treatment of ringworm by croton-oil is most fully detailed. The writer, Dr. Ladreit de Lacharrière, recognising the difficulty of eradicating the trichophyton from the root-bulbs in chronic tinea tonsurans by the ordinary lotions, ointments, and applications, refers to the advantages of crotonoil in destroying the diseased hairs and stumps by a process of suppuration (or an artificial kerion), while leaving the follicles intact. $\mathrm{He}$ states that the treatment was successful in eighteen cases, the duration of treatment lasting from six weeks to two months; and the cases treated, as I have already stated, were of the tender age of from two to five years.

Instead of employing the pure oil, as I have done, Dr. Ladreit de Lacharrière thinks better results are to be obtained from using it mixed with cacao-butter and white wax, in the proportions of 100 parts of the oil to 50 parts each of the adjuncts; and he advises that it should be made in moulds, so as to resemble a stick of cosmetique, as thereby the croton-oil can be applied with great accuracy as to both extent and depth.

It would be interesting if further experience of this method were forthcoming, more particularly at the present time, when attention is being directed to the therapeutics of ringworm, and while the merits of a rival non-irritating application (in the shape of thymol, as recommended by Mr. M. Morris) are before the profession.

\section{TRIPIER'S AMPUTATION OF THE FOOT.}

By P. J. HAYES, F.R.C.S.Ed., Surgeon to the Mater Misericordiz Hospital, etc.

THE description of a case, in which subastragalar amputation was performed, according to the method proposed by Dr. L. Tripier of Lyons, may be deemed worthy of notice, particularly as I believe this to be the first occasion on which the operation was subjected to the test of practice.

A countrywoman, aged 65, suffering from an epithelioma of large size, affecting the anterior and outer parts of the left foot, was admitted into the hospital on April 6th, 1880. The patient, though pale, did not present a cachectic aspect, and the lymphatics seemed free from traces of secondary deposit. As regards the history of her disease: twelve or thirteen months previously she observed a small hard tumour in the sole of her left foot, near the base of the fourth toe. This tumour gradually increased in size. The skin covering it became of a dark-greenish hue, and pressure 'upon it caused the patient great suffering. At length ulceration occurred at two points, and the openings gave vent to a foetid blood-stained fluid. A "cancer-curer" was invited to treat the case; but the applications employed by him, though they caused pain, proved futile; and the woman, ultimately acting on the advice of a medical practitioner, became an inmate of the Mater Misericordiæ Hospital.

In the number of the London Medical Record for April 15 th, I880, will be found a lucid description of Tripier's amputation, written by Mr. Wagstaffe of Si. Thomas's Hospital. Impressed by this article, and judging my patient to be just the kind of case for which the new operation would prove suitable, I resolved to practise it without delay. On April 2oth, the patient having been brought under the influence of ether, and Esmarch's cord having been adjusted, I commenced an incision at the outer border of the tendo Achillis, on a plane one inch and a quarter below the point of the external malleolus. This incision was carried through the skin and subcutaneous tissue, in a direction at first forwards, then upwards, forwards, and inwards-so as to pass two finger-breadths above the projecting base of the fifth metatarsal bone, and to terminate on the inner side of the tendon of the extensor proprius pollicis, cver the tarsal end of the corresponding metatarsal bone. The next incision was made from where the previous one terminated, in a direction downwards and forwards, so as to enter the inner part of the sole, one inch in front of the first tarso-metatarsal articulation. It was then carried outwards beneath the metatarsal bones; and, lastly, backwards, so as to join the first incision over the outer side of the os calcis. The deeper structures, corresponding to the dorsal wound, were next divided; then the knife was made to sever all the soft parts, from the plantar incision down to the bones; and, afterwards, a thick inferior flap was carefully raised until the under surface of the os calcis was exposed. At this stage, disarticulation of the scaphoid and cuboid from the astragalus and os calcis was effected, and separation of the plantar flap was continued until the point of the heel was turned; then the periosteum, covering the inferior aspect of the calcaneum, was incised in the antero-posterior direction, and detached from the bone up to the level of the sustentaculum tali. The exposed bone was divided, from within outwards, by means of Professor Spence's saw, so as to leave a broad flat surface level with the sustentaculum. All sharp angles were rounded off; whilst, to provide against the possible formation of neuroma, a high section of the posterior tibial nerve was effected from the deep surface of the plantar flap. The arteries were ligatured with carbolised catgut; the raw surface was everywhere bathed with a one-in-forty solution of carbolic acid ; catgut sutures were used for the purpose of keeping the flaps in apposition; and a drainage-tube was inserted at the posterior angle of the wound, close to the cuter edge of the tendo Achillis. Antiseptic dressings were employed for some days; and it only remains for me to add, that, within a month from the date of operation, the patient was able to walk about with the aid of crutches. The stump is now in a most satisfactory condition, being broad, even, and steady; whilst the movements of the ankle-joint are free and perfect as ever.

Surgeons who may desire full information respecting the arguments in favour of the new method, as contrasted with Chopart's and ordinary subastragalar amputation, will find an excellent résumé in Mr. Wagstaffe's paper. The experience derived from this first case induces me to form a high estimate of Dr. Tripier's amputation. It seems to possess all the advantages which have been claimed for it by the author.

\section{PATHOLOGICAL MEMORANDA.}

\section{WORM-LIKE BODIES FROM THE BLADDER.}

WITH reference to the case of "worm-like bodies from the bladder", recently brought before the Glasgow Pathological Society by Dr. Foulis, and reported in the JOURNAL of the 12 th instant, may I be permitted to suggest that, however closely these bodies may resemble "arteries" in their microscopical appearances, it is scarcely possible that they should in reality be such structures. Is not the explanation of their true nature to be found in the following passage from Boerhaave's Institutes? He says: "When blood extravasated into the pelvis of the kidney congeals into grumes, as they pass from thence into the ureter and bladder, an obstruction is by this means generally formed either in the ureter or urethra. I have myself seen blood concreted so as to put on the shape of a worm in the urethra, from whence we were obliged to extract it by a hook. Of this disorder died that considerable anatomist, Drelincourt:"

I may add that, shortly before I met with the foregoing extract from Boerhaave, Dr. King of this town showed me some bodies, of a curiously vermiform appearance, which were passed from the bladder by a male patient of his. I had no opportunity of examining them closely at the time, but I have now little doubt that they were portions of decolorised clot, which had been moulded in the ureter.

Notwithstanding what I may call their histological mimicry of "arteries", it seems at least highly probable that the specimens which were exhibited at Glasgow also consisted of fibrin, and had assumed their peculiar conformation in the ureter.

George F. Elliott, M.D., Hull.

\section{CLINICAL MEMORANDA.}

\section{ON THE PERIOD OF INCUBATION IN TYPHUS FEVER:}

THE following notes speak for themselves.

Mrs. B., aged 33, was admitted to the City of Glasgow Fever Hospital on January 22nd, 1879 , with a severe attack of typhus fever. On January 29th, I had a communication from Dr. Russell, Medical Offcer of Health for Glasgow, regarding this woman and her husband's brother, who was a patient in the hospital. It seems that a girl named $\mathrm{K}$., a niece of Mrs. B., had typhus in Port Glasgow, and, when convalescent, she came up to Glasgow, and stayed a night with the B.'s. That visit was the means of communicating the disease to the B.'s ; and Dr. Russell wished to ascertain the period of incubation in these cases. The facts are these. Agnes K., convalescent from typhus, stayed a night in the house of the B.'s (December 26th, 1878); Mrs. B. was admitted here on January 22nd, on the tenth day of illness. The period of incubation in this case was seventeen days. The lad B. was admitted at the same date, on the fifth (?) day of illness. The period of incubation was twenty-two days.

Jane S., nurse, was admitted on February 28th, I\$79 (Friday). This 